\title{
O irmão/pai de uma desaparecida política
}

\author{
The brother/father of a desaparecida
}

Graziele FREDERICO*

Università degli Studi di Milano

RESUMO: Os arquivos reunidos pela Comissão Nacional da Verdade expõe a busca labiríntica de Majer e Bernardo Kucinski por Ana Rosa e Wilson, desde 22 de abril de 1974. Como podemos ler no material recolhido, os familiares buscaram notícias e apelaram sem sucesso nos últimos quarenta anos para autoridades estrangeiras e nacionais. A postura do regime foi sempre negar a prisão e de alguma maneira vincular os desaparecidos, como subversivos. Também Bernardo Kucinski foi fichado por suas posições e pelo "incômodo" que vinha causando à imagem do governo ditatorial. Posteriormente, já na redemocratização, a Marinha divulgou um relatório acusando Ana Rosa de ter sido vítima do serviço secreto estadunidense em resposta aos trabalhos que ela supostamente realizaria para o governo israelense. Mais uma mentira, que como escreveu na época Bernardo Kucinski, visava mais uma vez impedir que se soubesse a verdade e negavam a memória de que ela lutara contra a ditadura militar e por isso foi detida, tortura, assassinada e desaparecida.

PALAVRAS - CHAVE: arquivo, memória, ditadura, Kucinski.

ABSTRACT: The files gathered by the National Truth Commission presented Majer and Bernardo Kucinski's labyrinthine search for Ana Rosa and Wilson since April 22, 1974. As we can read in the material, they sought for information and unsuccessfully appealed to foreign and national authorities. The regime's stance has always been to deny imprisonment and somehow link the disappeared because their subversives' activities. Bernardo Kucinski was also filed by the police for his politic positions and for the "inconvenience" he caused to the image of the dictatorial government. Later, as part of the post-dictatorship process, the Navy released a report accusing Ana Rosa of having been a victim of the US secret service in response of the work she

\footnotetext{
* Doutoranda em Estudos linguísticos, literários e interculturais no âmbito europeu e extra-europeu na Università degli Studi di Milano. E-mail: graziele.frederico@gmail.com https://orcid.org/0000-0002-3452 $\underline{4051}$
} 
supposedly would carry out for the Israeli government. One more lie, which as Bernardo Kucinski wrote at the time, aimed once again to prevent the truth from being known and denied the memory tha Ana Rosa had fought against the military dictatorship and for that reason was detained, tortured, murdered, and disappeared.

KEYWORDS: archive, memory, dictatorship, Kucinski.

\section{INTRODUÇÃO}

No romance $K$., Bernardo Kucinski reflete no capítulo "Imunidades, um paradoxo" sobre o hiato que transforma radicalmente a identidade de um sujeito quando se vê obrigado a enfrentar a "muralha do silêncio" de ter um familiar sequestrado e desaparecido pela repressão política. O narrador conta que no início da busca há esperança e uma postura cautelar com as autoridades. Depois, o familiar passa a empregar todos os esforços possíveis para conseguir notícias, mesmo que sejam apenas a confirmação da morte e a devolução de um corpo. Sua identidade é transformada.

\footnotetext{
Ao deparar na vitrine da grande avenida sua própria imagem refletida, um velho entre outros velhos e velhas, empunhando como um estandarte a fotografia ampliada da filha, dá-se conta, estupefato, da sua transformação. Ele não é mais ele, o escritor, o poeta, o professor de iídiche, não é mais um indivíduo, virou um símbolo, o ícone do pai de uma desaparecida política (Kucinski, 2012, p.90)
}

Fora da ficção, o sequestro de Ana Rosa, fez com que Kucinski retornasse do exílio voluntário em Londres e junto ao pai, começaram um percurso labiríntico que nem mesmo a Comissão Nacional da Verdade, encerrada em 2014 - quarenta anos depois do desaparecimento - apresentou uma saída. De acordo com o Acervo Vladmir Herzog e os dados obtidos até 2014, Ana Rosa e Wilson se encontraram para o almoço no centro de São Paulo, no dia 22 de abril de 1974, próximo à Praça da República, foram detidos pelos agentes da repressão, levados ao Departamento de Polícia Política de São Paulo, onde foram brutalmente torturados. Desde lá, não foram vistos por amigos e parentes. Em agosto de 1974, os familiares entraram com pedidos de habeas corpus, que foi negado pelo Superior Tribunal Militar. Dom Paulo Evaristo Arns, cardeal e arcebispo de São 
Paulo, conseguiu a promessa do ministro da Casa Civil, Golbery do Couto e Silva que seria feita uma averiguação do caso.

Em setembro, Bernardo e Majer Kucinski pediram a colaboração do ex-Ministro do Exterior de Israel, Abba Ebban, que solicitou ao governo brasileiro notícias sobre o paradeiro de Ana Rosa e Wilson. Na mesma época, chegaram requisições da mesma natureza pelo Comitê de Organizações e Movimentos Internacionais da Casa dos Representantes do Congresso dos Estados Unidos e da Seção Americana do Congresso Judaico Internacional. Todas informavam que os familiares denunciavam a prisão do casal pelo II Exército de São Paulo e a transferência para a sede da Operação Bandeirantes, onde teriam sido torturados, "encontrando-se com a saúde abalada e distúrbios mentais, além de incomunicáveis"1. Em novembro do mesmo ano, Bernardo Kucinski protocolou um pedido formal na Comissão Interamericana de Direitos Humanos para abertura de investigação do governo brasileiro com relação à recusa do habeas corpus e informações sobre o paradeiro de Ana Rosa e Wilson. No dia 13 de dezembro, Majer Kucinski escreveu uma carta pedindo ajuda e intervenção do senador Franco Montoro. Em tom emocionado, ele contou ter lido o discurso proferido pelo parlamentar em ocasião do $25^{\circ}$ aniversário da Declaração Universal dos Direitos Humanos.

\footnotetext{
${ }^{1}$ Tais informações estão presentes nas correspondências enviadas ao Ministério da Justiça em cartas endereçadas ao Ministro Armando Ribeiro Falcão, presentes no arquivo do caso Ana Rosa Kucinski da Comissão Nacional da Verdade.
} 
Figura 1. Carta de Majer Kucinski enviada ao Senador Franco Montoro (MDB) pedindo ajuda nas buscas por informações do paradeiro de Ana Rosa Kucinski e Wilson Silva.

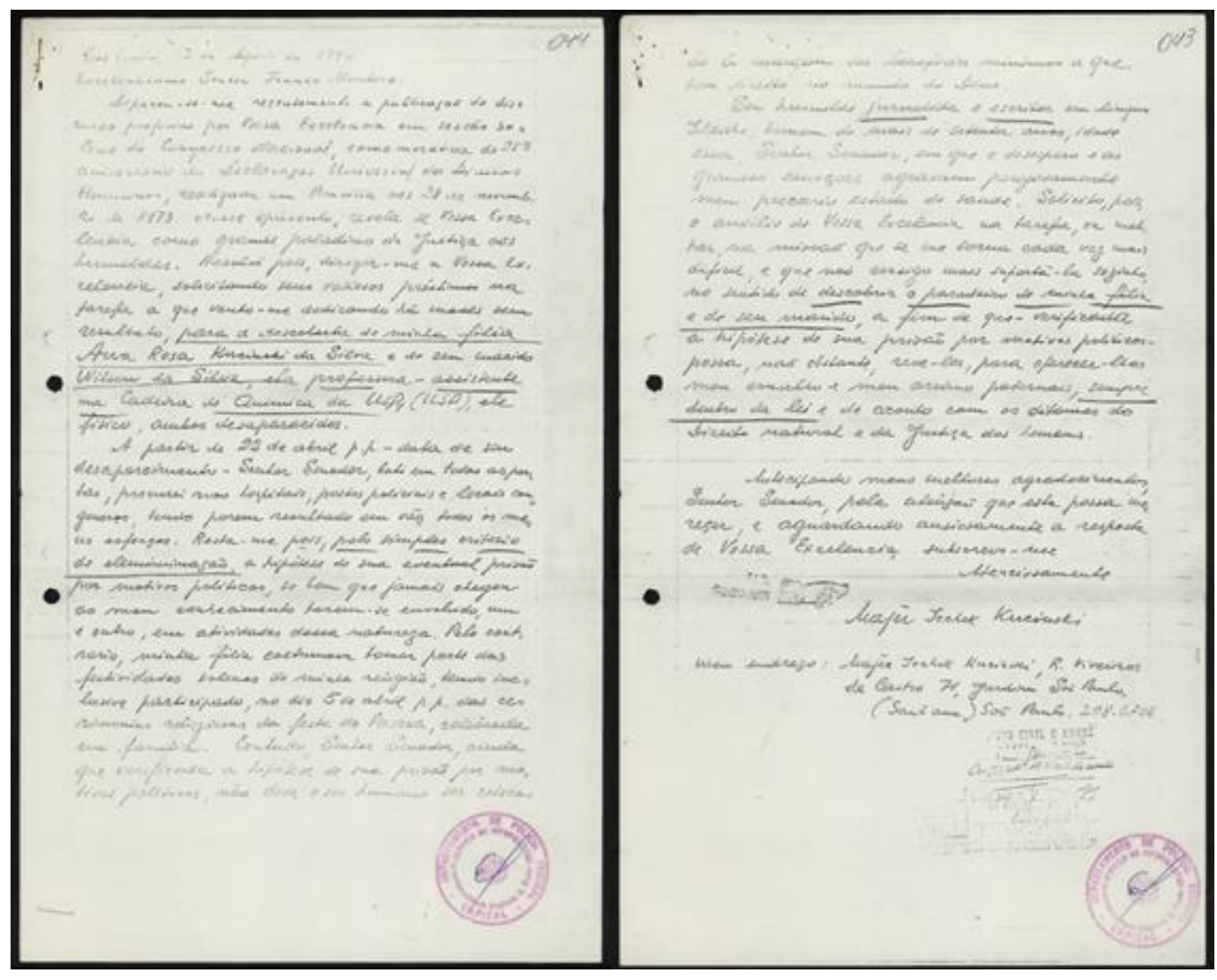

Fonte: Arquivo Comissão Nacional da Verdade.

Nesse episódio, revela-se Vossa Excelência como grande paladino da Justiça aos humildes. Ressoei, pois, dirigir-me a Vossa Excelência, solicitando seus valiosos préstimos na tarefa a que venho-me dedicando há meses sem resultado, para a descoberta de minha filha Ana Rosa Kucinski Silva e de seu marido Wilson Silva, ela professora assistente na Cadeira de Química da USP, ele físico, ambos desaparecidos. A partir de 22 de abril - data de seu desaparecimento - Senhor Senador, bati em todas as portas, procurei nos hospitais, postos policiais e locais congêneres, tendo, porém, resultado em vão todos os meus esforços. Resta-me, pois, pelo simples critério de eliminação, a hipótese de sua eventual prisão por motivos políticos, se bem que jamais chegou ao meu conhecimento terem-se envolvido, um e outro, em atividades dessa natureza. Sou um humilde jornalista e escritor em língua iídiche, homem de mais de setenta anos, idade essa, Senhor Senador, em que o desespero e as grandes emoções agravam perigosamente meu precário estado de saúde. Solicito, pois, o auxílio de Vossa Excelência na tarefa, ou melhor, na missão que me torna cada vez mais difícil, e que não consigo mais suportá-la sozinho 
no sentido de descobrir o paradeiro de minha filha e de seu marido, a fim de que - verificada a hipótese de sua prisão por motivos políticos, possa, não obstante, revê-los, para oferecer-lhes meu conselho e meu arrimo paternais, sempre dentro da lei e de acordo com os ditames do direito natural e da justiça dos homens (Majer Kucinski, 1974, s.p.).

A partir das demandas vindas tanto do Ministério das Relações Exteriores, como do senador Montoro e das organizações internacionais, o Ministério da Justiça pediu a abertura de uma investigação sobre a prisão de Ana Rosa e Wilson. Em menos de dez dias, o ministro Falcão encaminhou aos órgãos competentes a informação que recebeu da Direção-Geral do Departamento da Polícia Federal: “o referido casal não está nem esteve preso em dependências do Departamento Estadual de Ordem Política e Social de São Paulo - DEOPS/SP ou da Superintendência Regional da Polícia Federal naquele Estado". Ainda assim, o Ministério das Relações Exteriores acionou novamente a Justiça pedindo que se fizesse algo, alertando que os familiares continuavam fazendo referência ao caso na imprensa nacional e internacional. Em anexo, os diplomatas apresentavam os anúncios divulgados por Majer Kucinski pedindo notícias e informações sobre a filha e o genro.

Figura 2. Há um erro na data do anúncio, que é de 10 de janeiro de 1974 e saiu nas edições de $O$ Estado de S.Paulo e Jornal do Brasil. Este último, como exibido na imagem, foi publicado na edição 280 de 15 de janeiro de 1975.

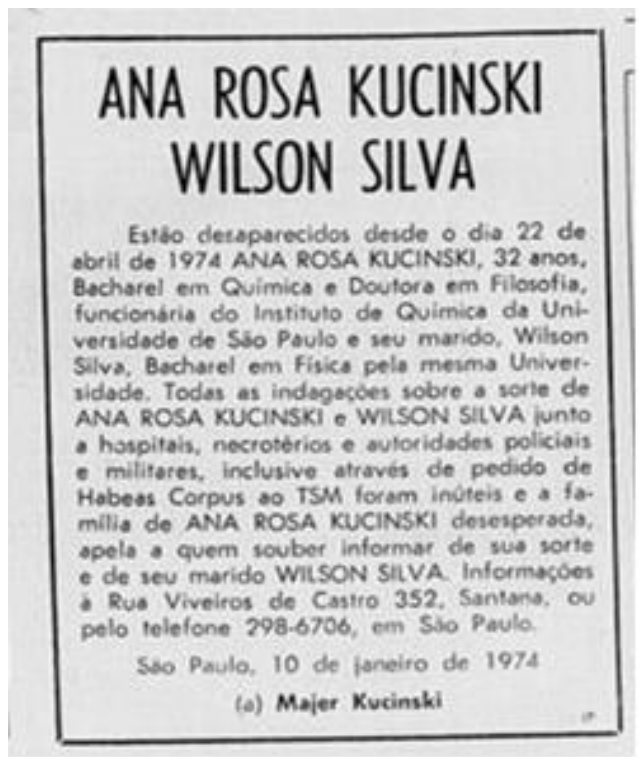

Fonte: Acervo da Biblioteca Nacional. 
Figura 3

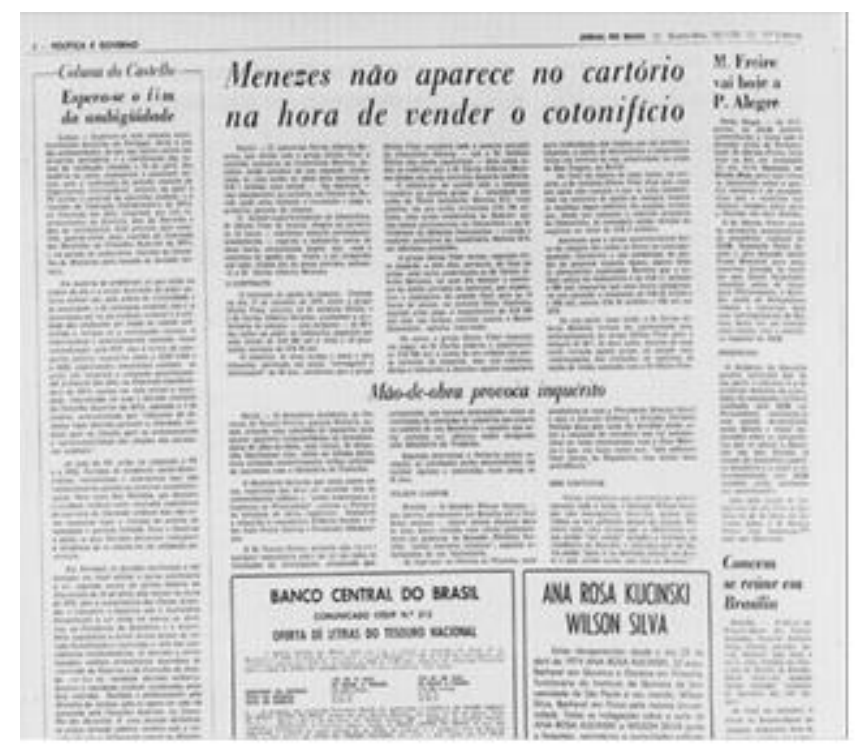

Fonte: Acervo da Biblioteca Nacional.

Na tentativa de abafar o caso, o Ministério da Justiça divulgou no dia 6 de fevereiro de 1975, uma nota oficial com informações sobre 23 pessoas que eram tidas como desaparecidas. Sobre Wilson Silva, os dados dos órgãos de Segurança apontavam que além de físico, era um dos redatores do jornal Voz operária, sobre Ana Rosa Kucinski, não havia nenhum registro. Cinco meses depois, a Comissão Interamericana de Direitos Humanos enviou novo aviso solicitando que até dezembro o governo brasileiro retomasse as investigações sobre o paradeiro de Ana Rosa e Wilson e apresentasse um novo parecer formal sobre o caso. Majer Kucinski tentou uma última vez apelar às autoridades do Exército brasileiro, quando em março de 1976 aguardou nas escadarias da porta principal da Cúria Metropolitana de São Paulo, a saída do general Dilermando Gomes Monteiro que se encontrara com Dom Paulo Evaristo Arns. Majer entregou a ele uma carta pedindo que o ajudasse a encontrar a filha. O general entrou rapidamente no carro e deixou a sede da igreja despedindo-se de Dom Paulo, pedindo que não se esquecesse de abençoá-lo. Nesse mesmo período, o procurador da Justiça Militar Darcy de Araújo Ribeiro aceitou a denúncia para processar por extorsão o comerciante Flávio Ferreira da Silva, o sargento do II Exército, José Sanches Valejo, o advogado Roberto Damiani, o policial ferroviário Ubirajara Ribeiro da Silva, o policial militar reformado 
Romão Guilherme Filho e a sargento da Polícia Feminina, Nair de Carvalho Ferreira da Silva.

De acordo com notícia publicada pelo jornal Folha da Tarde ${ }^{2}$, o advogado comentou com o comerciante sobre as dificuldades de encontrar notícias de Ana Rosa e este, respondeu que tinha muitos contatos no Exército e na polícia política o que poderia lhe render alguma informação. Foi então que, Flávio Ferreira da Silva entrou em contato com Valejo e ambos foram ao Quartel General do II Exército, em São Paulo e pediram que um dos sargentos que conheciam investigasse a detenção de Ana Rosa. Saindo dali, decidiram pedir 50 mil cruzeiros pelas informações que conseguissem. O advogado resolveu acrescentar mais 15 mil cruzeiros para contar a família sobre o paradeiro de Ana Rosa. Ligou ao cliente e Bernardo Kucinski aceitou pagá-los. Mesmo quando foram convencidos que Ana Rosa não estava nas dependências do Exército em São Paulo, os informantes decidiram manter uma história para poderem receber o dinheiro. Ao contarem para Bernardo Kucinski que sua irmã encontrava-se presa, esse exigiu uma prova, um bilhete escrito de próprio punho. Foi então que Flávio resolveu envolver a esposa Nair, que era sargento da Polícia Feminina, para que redigisse a prova pedida. Ao receber o bilhete, Kucinski desconfiou que aquela não era a caligrafia da irmã e insistiu em mais uma evidência, pediu que conversassem com Ana Rosa e perguntassem qual era seu apelido na família. Insistindo na possibilidade de ainda conseguir o dinheiro, os supostos informantes tentaram uma resposta, que estava bem longe de ser a verdadeira. Sabendo que a vítima não estava acreditando no golpe, o grupo resolveu incrementar a farsa trazendo ao encontro de Kucinski o policial reformado Romão Guilherme Filho, interpretando o papel de um coronel importante na corporação em companhia de Ubirajara da Silva para interpretar o motorista. Ciente da mentira da qual fora vítima, Kucinski denunciou o bando por extorsão.

A acusação contra o comerciante, o advogado e os respectivos agentes constava no prontuário que o Comando do II Exército abriu em nome de Bernardo Kucinski. No documento, esta informação era tida como mais um dos fatos que o jornalista criara, "com o objetivo de denegrir a imagem dos Órgãos de Segurança”. Kucinski estava fichado também pela denúncia que tinha feito na Comissão Interamericana de Direitos Humanos e pela participação no seminário "Jornalismo Econômico e as multinacionais". Segundo

\footnotetext{
${ }^{2}$ Fonte: "Policiais denunciados por extorsão", Folha da tarde, p.2 de 11 de maio de 1976.
} 
o documento, em 11 de agosto de 1975, o jornalista comunicou ao público que seguiria os conselhos lidos em um livro de um colega norte-americano, de "ter por princípio a desconfiança em todos os atos que o governo praticasse e roubar sempre que possível documentos secretos, para poderem assim tornar suas reportagens mais verídicas. Passaria a desconfiar dos atos do governo, mesmo que eles fossem praticados em boa fé e ressaltou que o presidente Geisel, no caso das multinacionais está agindo de modo ingênuo". Anos depois, a Marinha incluiu entre as suspeitas contra Kucinski, a possibilidade que ele transmitisse informações sobre o programa nuclear brasileiro para o serviço secreto israelense.

Majer Kucinski não viu essa nem outras acusações que foram feitas nos anos seguintes a seus filhos. Ele faleceu em 29 de setembro de 1976. No obituário, os familiares destacaram que a morte, aos 72 anos, chegara "após dois anos e meio de sofrimento com o desaparecimento de sua filha". ${ }^{3}$ Nove anos depois, em abril de 1987, o médico-tenente Amílcar Lobo fez menção de ter visto Wilson Silva entre os mortos da Casa da Morte de Petrópolis - um dos centros clandestinos de tortura e assassinatos da repressão. Seis anos mais tarde, em depoimento à Comissão Especial de Mortos e Desaparecidos, Bernardo Kucinski repassou as informações que as investigações de quase duas décadas reportavam sobre o caso da irmã: Ana Rosa e Wilson Silva foram presos na tarde de 22 de abril de 1974 por José Rodrigues Gonçalves, cabo reformado do Exército. Ainda naquela madrugada, ambos foram levados para Petrópolis pelos policiais Ênio Pimentel da Silveira e Sérgio Paranhos Fleury. Nessa mesma época, em 1993, um relatório divulgado pela Marinha informava que Ana Rosa teria sido sequestrada pela Central Intelligence Agency, a CIA estadunidense, pelo trabalho que desenvolvia tanto na militância em organizações brasileiras como pelas informações que repassava a agentes israelenses. Em 15 de dezembro de 1993, Bernardo Kucinski publicou o artigo “Tortura, ontem e hoje" no jornal a Folha de S.Paulo, contestando o desrespeito e a difamação do relatório.

Há 19 anos sofro com o desaparecimento de minha irmã, Ana Rosa Kucinski e seu marido Wilson Silva, ativistas da Ação Libertadora Nacional (ALN), presos pela repressão em São Paulo e levados para a casa-prisão onde foram

\footnotetext{
${ }^{3}$ Fonte: $O$ Estado de S. Paulo, 30 de setembro de 1976, p.45.
} 
esquartejados, conforme o depoimento do ex-sargento Manoel Chaves [Marival], na revista Veja de 18/11/93, e outros testemunhos. Seu jornal, em matérias de Mário Simas Filho, deu grande destaque a um trecho de um relatório da Marinha que diz ter sido minha irmã morta pela CIA e não pela repressão doméstica. Para vender a mentira, a Marinha alega que tanto ela como eu passavam 'informações sobre o avanço da tecnologia nuclear brasileira para Israel'. Nem o repórter nem o jornal deram-se ao cuidado de checar as alegações. Lamento que um deputado do partido a que pertenço, do PT [Partido dos Trabalhadores], tenha tão ingenuamente disseminado o relatório da Marinha. Sr. Editor, não tenho sequer onde venerar a memória da minha irmã, pois seus restos foram espalhados não se sabe onde. Não posso pedir a punição de seus assassinos, pois foram anistiados coletivamente e por antecipação. Agora tenho que pedir que não tirem dela o direito de ter morrido como ativista da Ação Libertadora Nacional. Parem de torturar. Tortura, nunca mais (Kucinski, 1993, p.1).

Na Comissão Nacional da Verdade, Marival Chaves confirmou que Ana Rosa e Wilson foram levados vivos para a Casa da Morte. Eles e outros militantes da Ação Libertadora Nacional foram delatados pelo agente infiltrado João Henrique Ferreira de Carvalho, conhecido como Jota, que depois se tornou médico e atuou na cidade de Brasília. Os nomes de Ana Rosa e Wilson são citados também no livro de memórias do ex-delegado Cláudio Guerra, Memórias de uma guerra suja (2012), onde ele contou ter participado da incineração de seus corpos na Usina Cambahyba que pertencia ao exdeputado federal e ex-vice-governador do estado do Rio de Janeiro, Heli Ribeiro Gomes. No relatório final, a Comissão recomendou que as investigações sobre o caso de Ana Rosa continuassem "para a localização de seus restos mortais e identificação e responsabilização dos demais agentes envolvidos” (Brasil, 2014, p.1652).

\section{REFERÊNCIAS}

ACERVO Vladmir Herzog. Ana Rosa Kucinski Silva. Disponível em: Ana Rosa Kucinski Silva - Memórias da ditadura (memoriasdaditadura.org.br) Acesso em: 19 de novembro de 2021.

BRASIL, Relatório da Comissão Nacional da Verdade, vol.3, p.1652, 2014. 
COMISSÃO NACIONAL DA VERDADE. Arquivos Ana Rosa Kucinski, Bernardo Kucinski. Rio de Janeiro, 2014.

KUCINSKI, Bernardo. K. São Paulo: Expressão Popular, 2012.

KUCINSKI, Bernardo. Tortura, ontem e hoje. Folha de S.Paulo. São Paulo, 15 de dezembro, p.1, 1993.

KUCINSKI, Majer. Anúncio: Ana Rosa Kucinski e Wilson Silva. Jornal do Brasil. Rio de Janeiro, 15 de janeiro, n.280, p.4, 1975.

REDAÇÃO. Policiais denunciados por extorsão. Folha da Tarde. São Paulo, 11 de maio, p.2, 1976. 